\title{
Pleural Effusion in Lung Cancer: More Questions than Answers
}

\author{
Marios E. Froudarakis \\ Department of Pneumonology, Medical School, Democritus University of Thrace, Alexandroupolis, Greece
}

\section{Key Words}

Pleural effusion · Lung cancer · Non-small-cell lung carcinoma - Target therapy • Tyrosine kinase inhibitors • Epidermal growth factor receptor $\cdot$ Vascular endothelial growth factor - Matrix metalloproteinase $\cdot$ Cyclooxygenase

\begin{abstract}
Lung cancer remains the most common fatal malignancy, despite more aggressive therapies. Few patients will survive 5 years, as up to $80 \%$ of the patients will present with advanced-stage disease at diagnosis. Chemotherapy offers little benefit in terms of median survival and disease-free survival in patients with advanced-stage non-small-cell lung carcinoma (NSCLC). In the last decade, the development of new targeted therapies based on the better understanding of different paths of carcinogenesis has given new hope to both physicians and patients. Metastatic pleural effusion from lung cancer has a particularly poor prognosis, and in NSCLC it is actually reclassified as stage IV disease. A possible explanation of this observation is differences in the genomics between primary tumors and metastasis, leading to possible different therapeutic approaches with novel molecular therapies in this patient population. The current review aims to summarize the actual situation of research in pleural disease due to lung carcinoma in relation to novel targeted therapies tested in this patient population.
\end{abstract}

Copyright $\odot 2012$ S. Karger AG, Basel
(C) 2012 S. Karger AG, Basel

0025-7931/12/0835-0367\$38.00/0

Fax +4161306 1234

E-Mail karger@karger.ch

www.karger.com
Accessible online at:

www.karger.com/res

\section{Introduction}

Lung cancer remains the most common fatal malignancy, despite more aggressive therapies. Patients with non-small-cell lung carcinoma (NSCLC) undergoing radical surgery comprise around $10 \%$, and these are likely to be cured. In advanced-stage disease, first-line chemotherapy has shown little improvement in survival, and second-line chemotherapy in a few patients in a good condition has globally shown little effect. In patients with small-cell lung carcinoma (SCLC), chemotherapy showed important results in terms of response. However, the effect on patients' survival is globally poor, as a small percentage of patients with local disease and aggressive therapy combining chemotherapy with mediastinal and cranialirradiation hopeto survive at 5 years. The development of novel targeted therapies has given new hope to both physicians and patients $[1,2]$.

Previous articles in this series: 1. Anevlavis S, Tzouvelekis A, Bouros D: Mechanisms of pleural involvement in orphan diseases. Respiration 2012;83:5-12. 2. Rodriguez-Panadero F, Montes-Worboys A: Mechanisms of pleurodesis. Respiration 2012;83:91-98. 3. Grundy S, Bentley A, Tschopp JM: Primary spontaneous pneumothorax: a diffuse disease of the pleura. Respiration 2012;83:185-189. 4. Haas AR, Sterman $\mathrm{DH}$ : Novel intrapleural therapies for malignant diseases. Respiration 2012;83:277-292. 
In patients with lung cancer, the incidence of pleural effusion ranges between $7 \%$ ( 280 out of 4,000 cases) and $23 \%(5,888$ out of 25,464 cases) [3]. Similarly, in a study of patients presenting with malignant pleural effusion, lung cancer was the most frequent cause (641 out of 1,783 patients; $36 \%$ ), while the second most common cause was breast carcinoma (449 cases; 25\%) [4]. All histological types of lung carcinomas are likely to cause pleural effusion [3]. The most frequent histological type seems to be adenocarcinoma (40\% of the cases), with SCLC second, in about $25 \%$ of the cases [3]. Adenocarcinoma is actually the commonest histological type of NSCLC; also, it is more likely to arise in the lung periphery invading the pleura [5].

Recently, the International Association for the Study of Lung Cancer Lung Cancer Staging Project reviewed the T and M stage of 18,198 NSCLC patients. The number of patients with pleural dissemination - classified as T4 according to Mountain's revised classification - was 471 . Five-year and median survival for those patients were $2 \%$ and 8 months, respectively, versus $14 \%$ and 13 months for clinical T4 disease other than pleural effusion $(p<0.0001)$. According to these data, the patients were reclassified as having M1a disease [6], since their outcome was the same as in distant metastasis [7]. In SCLC, median survival of patients with limited disease and ipsilateral malignant pleural effusion (12 months) is worse than in patients with limited-stage disease without pleural effusion (18 months) but better than those with extensive disease ( 7 months; $p$ $=0.0001$ ) [8-10]. The reasons for this intermediate prognosis should be clarified by further clinical trials [11].

Overall, different clinical staging systems may indicate different survival in lung cancer patients showing pleural involvement; however, they cannot explain the aggressive behavior of pleural disease, despite the disease remaining in the same hemithorax. The explanation might be given by the study of novel molecular factors of different pathways of carcinogenesis, and the differences in this status between primary tumors and metastasis, leading to application of novel molecular therapies in this patient population. Many of those factors have already been assessed in the last decade in patients with metastatic pleural effusion, most of them to differentiate exudates from transudates and/or to increase the diagnostic yield of pleural cytology [12]. However, the results are difficult to apply in lung carcinoma pleural effusions, since they concern effusions from metastases of various primaries. The current review aims to summarize the actual situation of research in pleural disease due to lung carcinoma in relation to novel targeted compounds tested in this patient population.

\section{Epidermal Growth Factor Receptor Pathway}

The epidermal growth factor receptor (EGFR) gene is located on chromosome $7 \mathrm{p} 12.1-12.3$ in humans. It is a transmembrane tyrosine kinase receptor that is frequently expressed in various kinds of epithelial tumors [13]. Its expression is regulated by one promoter and two enhancer regions [14]. The signaling pathways of activated EGFR are involved in cancer cell proliferation, apoptosis, angiogenesis, invasion and metastasis, suggesting that EGFR is a target for molecular therapy. NSCLC accumulates multiple genetic alterations [15]. Within the tyrosine kinase domain, mutations of EGFR exons 19 and 21 may play an important role in NSCLC carcinogenesis, since it has been shown that they are related to prolonged survival, by increasing sensitivity to tyrosine kinase inhibitors (TKIs). In contrast, insertion mutation of exon 20 is associated with resistance to TKIs $[16,17]$.

Recent studies have defined clinicopathological variations in terms of response to TKIs, with adenocarcinoma, nonsmokers, females and Asians being more likely to respond to therapy $[17,18]$. This patient population has been associated with higher rates of EGFR mutations. Also, it has been shown that the expression of EGFR mutations might be used to predict responsiveness to TKI therapy. Identification of clinical and genetic factors underlying EGFR mutations will be particularly meaningful not only for understanding lung carcinogenesis in nonsmokers but also for making clinical decisions about the use of EGFR TKIs in nonoperative patients. Patients with EGFR mutations may benefit from better response and survival, independently of the treatment received [18].

Although in recent years there has been increased interest in EGFR mutations and their therapeutic applications in NSCLC, with more than 3,500 publications to date, few studies have reported data from patients with pleural metastasis from their carcinoma (table 1). All these studies involved Asiatic patients (Japan 5, Taiwan 4, PR China 1 and Singapore 1), with the rate of lung adenocarcinomas ranging between 85 and 100\%. Exons studied were 18, 19, 20 and 21, and findings varied according to the study. Overall, observed mutation rates ranged from 24 to $68.7 \%$ with a median of $34 \%$. These data are comparable to the mutation rates in other EGFR reports from Asiatic patients studying surgical $[19,20]$ and nonsurgical $[21,22]$ specimens $(32-55 \%)$. A recent study in Korea [23] comparing the EGFR status between the primary tumor and pleural metastatic disease showed a significant discordance of $16 \%$ between the primary tu- 


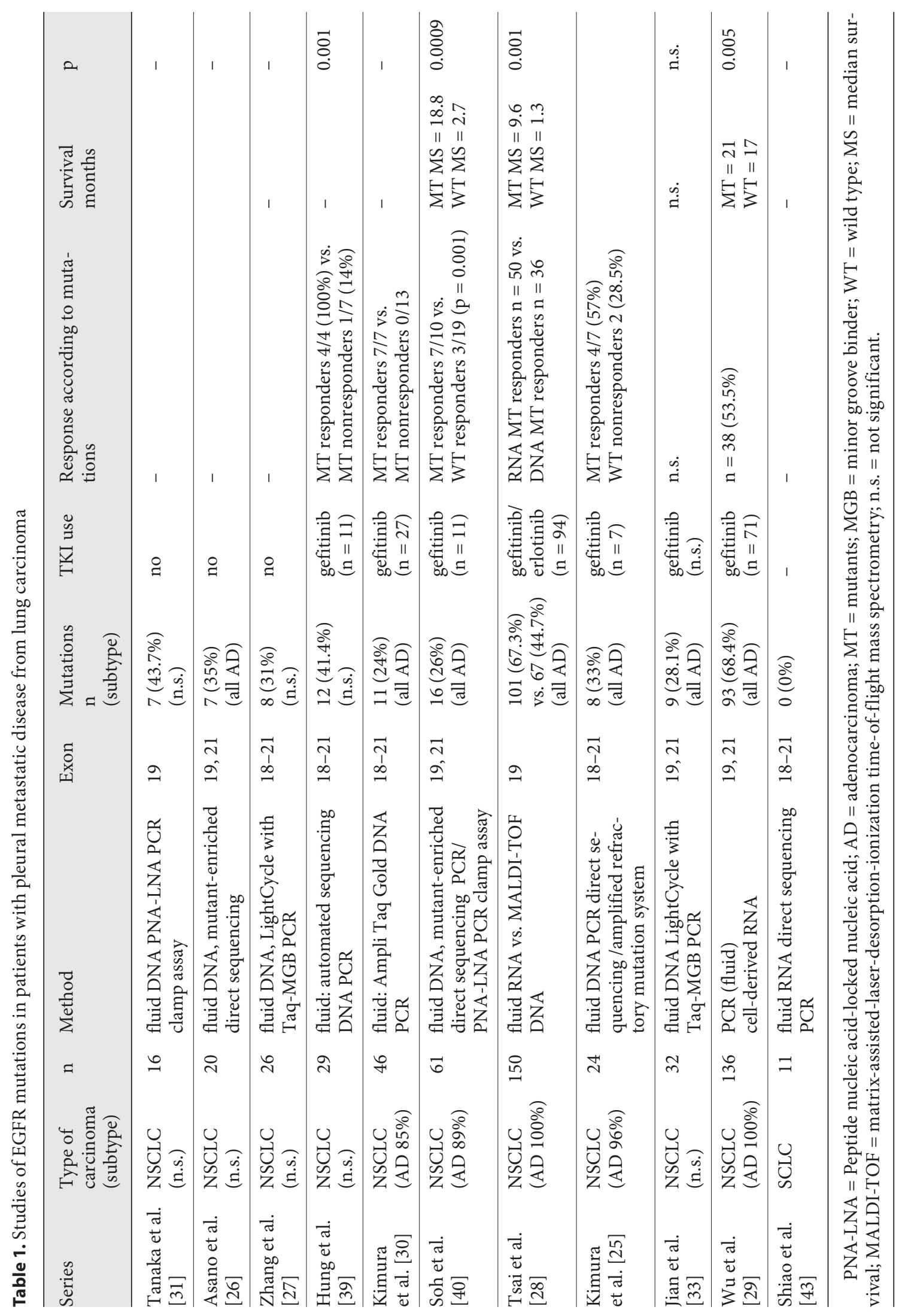


mor and pleural metastasis [23]. Although there has not yet been a study performed in Caucasians with pleural metastasis, we know that the prevalence of EGFR mutations in NSCLC Caucasian patients is lower, i.e. $16 \%$ in the primary tumor compared to $8 \%$ of nonpleural metastases [24]. However, this discordance not only varies according to the ethnicity but also to the organ involved in the metastatic process.

However, some observations might be interesting concerning those studies on pleural fluid cells:

- As expected, lesions on exons 19 and 21 were the most frequent observed. Exon 19 deletions (especially E746A750del) and exon 21 L858R substitution, which are already known to have a role in lung carcinogenesis, were present on pleural fluid cells. Those mutations accounted for $40-45 \%$ in patients with NSCLC. Also, E747-P753del ins and L747-T751del are minor variations of deletion mutations in exon 19 [25].

- Overall, few mutations or alterations were observed on exons 18 and 20, raising some questions regarding whether they are involved in metastatic pleural disease (or their role is not yet identified).

- Direct DNA sequencing from pleural effusion cells is currently the routine method used to detect EGFR mutations in pleural fluid. However, some of the studies used different methods, such as DNA from cell-free pleural fluid $[26,27]$ or RNA sequencing $[28,29]$, claiming that either they are more suitable for recognizing EGFR mutations, that they are complementary to classical DNA sequencing or involve lower costs [28, $30,31]$. This fact has a direct impact on the nonhomogenous methods to study EGFR mutations in pleural fluid, which therefore lead to variations in the rates of EGFR mutations reported.

- Whatever the method chosen, to initiate TKIs, the nucleotide sequence should be able to detect patients with heterozygous deletion, concerning in the case of exon 19 a deletion 746-750, and to detect a substitution of R858L on exon 21. Patients harboring the exon 19 deletion seem to respond better to TKIs than patients harboring the exon 21 mutation [32]. Also, the method should be accurate in recognizing the methionine to threonine substitution at position 790 (T790M), in order not to misdiagnose resistance in patients initially responsive to TKIs [33]. These mutations are critical factors for TKI treatment.

- All studies concerned DNA extraction from cancer cells of pleural fluid. However, we know that cytology of pleural fluid has a low diagnostic yield in patients with lung carcinoma, since the mean concentration of cancer cells in pleural fluid is about $40 \%[3,5]$. Therefore, there is a major limitation to applying this method in all pleural effusions as we may miss a good number of them. However, by using cytospin and/or cell blocks of pleural fluid for cytopathological diagnosis, in the case of lung adenocarcinoma pleural effusion, we may increase our diagnostic yield [34]. Many of the authors argued that to perform tissue studies is difficult, because of the low quantity of pleural tissue they can obtain for molecular studies, already of limited sufficiency for accurate histological diagnosis. This is certainly due to the use of blind or image-guided needle biopsies instead of minimally invasive techniques, such as thoracoscopy (either medical or surgical) [35]. Indeed, the size of blind or image-guided biopsies is not only small compared to those taken during thoracoscopy, but also the number of biopsies taken during thoracoscopy is far greater than that taken during noninvasive procedures $[36,37]$. However, in a recent study, the amount of DNA extracted from pleural fluid cells, although it was not specified whether the tap was diagnostic, looks sufficient to conduct molecular tests [38].

- Lung cancers are heterogeneous for EGFR mutations. In some patients, a small number of cancer cells with mutant alleles may exist among a large number of cancer cells with the wild-type alleles. The sensitivity of the method should be able to detect small numbers of mutants when heterogeneity exists; not only DNA from tumor cells but also DNA from other cell types (e.g. inflammatory cells) is included during extraction. However, it is not clear whether killing a small number of mutant cells provides any clinical benefit, while a large number of wild-type cells survive [31].

- Some of the studies shown in table 1 concurrently reported results of patients with administration of EGFR TKIs, according to their mutational status [25, $28-30,33,39,40]$. All concerned gefitinib, except one in which both gefitinib and erlotinib were evaluated [28]. In those studies, mutant responders were more frequent than wild-type responders. When median survival was assessed, mutant responders seemed to do better $[28,29,33,39,40]$. In the study of gefitinib/ erlotinib [28], no information is given regarding whether one compound performed better than the other or not. However, good performance status and EGFR mutations of L858R or exon 19 deletion were independent prognostic factors of better disease-free survival [28]. 
- There is no study reporting results from cetuximab (Erbitux), a monoclonal antibody against ligand binding in the extracellular domain of EGFR that inhibits tumor growth and showed promising results when administered with chemotherapy in advanced-stage NSCLC in a recent meta-analysis [41]. However, the cost-benefit ratio of cetuximab remains extremely high [42].

- Only one study reported results in only 11 patients with SCLC pleural effusion [43]. The authors were unable to identify mutations on exons 18, 19, 20 and 21, but this is a general characteristic of SCLC.

\section{Factors of Angiogenesis}

Tumor angiogenesis has an important role in tumor growth, progression and dissemination in both solid tumors and hematological malignancies. Formation of novel vessels is mandatory to provide nutritive substances and oxygen to the tumor in order to grow. Angiogenesis may occur either through endothelial and vascular sprouting or by endothelium-dependent intussusceptive microvascular growth [44]. Sprouting is a mechanism that involves the formation of new capillaries by preexisting vessels. In this type of angiogenesis, there is rupture of the basal membrane of the surrounding to tumor capillaries, followed by endothelial cell migration and proliferation to form new capillaries. Intussusceptive angiogenesis is a mechanism that involves division, enlargement and fusion of preexisting capillaries, with remodeling and expansion of new capillaries by the insertion of interstitial tissue into the lumen of preexisting vessels [45]. Endothelial cell precursors then migrate from the bone marrow or the peripheral circulation into the endothelium of new vessels. These mechanisms may present concurrently during tumor angiogenesis [44].

\section{Vascular Endothelial Growth Factor}

Angiogenesis is regulated by a number of angiogenic and antiangiogenic cytokines. An important factor during tumor angiogenesis is vascular endothelial growth factor (VEGF). VEGF expression is induced by hypoxia through hypoxia-inducible factor-1, platelet-derived growth factor, tumor necrosis factor- $\alpha$ and transforming growth factor- $\beta$ and by inactivation of the von HippelLindau tumor suppressor gene [46]. VEGF promotes angiogenesis by binding to three tyrosine kinase receptors, i.e. VEGF receptor-1 (VEGFR-1), VEGFR-2 and VEGFR-3. VEGFR-1 and VEGFR-2 are expressed on vascular endothelial cells, and their action is necessary to promote VEGF-dependent formation of novel vessels. VEGFR-2 signal transduction activates pathways that promote endothelial cell proliferation, cell survival and migration [46]. Recently, it has also been shown that VEGF is able to increase vascular permeability in the same way as vascular permeability factor [47]. Many studies have shown the important role of VEGF in the survival of NSCLC patients. The overexpression of VEGF in primary resected tumors correlates significantly with high microvascular density in the tumor, poor survival and early relapse in patients with NSCLC. Also, studies in patients with advanced NSCLC showed that expression of VEGF is inversely correlated with survival and disease-free survival. In recent years, a great number of clinical trials have tried to evaluate the efficacy of antiangiogenic compounds such as bevacizumab (humanized anti-VEGF antibody) in patients with NSCLC. It has been shown to improve survival in patients with advanced lung adenocarcinoma, in combination with chemotherapy [48].

Although many studies have reported results of VEGF levels in pleural effusions (either malignant or not), few data exist concerning metastatic pleural effusion from lung carcinoma. There is clear evidence that metastatic pleural effusions in lung cancer patients contain high levels of VEGF, and those levels are very much dependent on the stage of the disease $[49,50]$. In the clinical setting, not only do VEGF levels increase the diagnostic accuracy of pleural puncture in patients with malignant pleural effusion [51] and pleural metastasis from lung carcinoma [52], but also, increased VEGF levels are indicative of poor survival in this patient population [53]. In an experimental model of induction of malignant pleural effusion after injection of human lung adenocarcinoma cell lines, it has been shown that both VEGF and vascular permeability factor are responsible for new vessels and pleural effusion formation by inducing vascular hyperpermeability [54]. In another experimental model of a human lung adenocarcinoma cell line, an inhibitor of combined VEGFR-2/ EGFR (vandetanib) showed activity in reducing tumor cell proliferation and tumor vascularization while inhibiting pleural effusion [55]. Whether the inhibition of malignant effusion formation by anti-VEGF treatment is entirely a result of reduced vascular permeability or represents an indirect consequence of reducing tumor load (secondary to the antiangiogenic effects of VEGF inhibition) requires further investigation [56].

Another possible mechanism of pleural effusion formation is the induction of lymphangiogenesis by VEGF. VEGF binds VEGFR-3, which is produced by lymphatic 
endothelial cells and therefore seems to play an important role in forming new lymphatic vessels [44]. The role of the intratumoral or peritumoral lymphatics in the spread of the disease is controversial, because when observed they are immature in morphology, with small lumens, and contain very few endothelial cells. However, there are variations regarding the intratumor morphology and incidence of neolymphatics between the various human solid tumors (melanomas present with more lymphatics and head and neck tumors with very few) and between primary tumors (few lymphatics with small lumens) and distant metastases (high incidence with large lumen). As we know the crucial role of lymph circulation in the physiology and pathophysiology of the pleura and pleural diseases $[57,58]$, it is easily understandable why we should extensively study this possible mechanism in the formation of metastatic pleural effusion, with more specific explanation about why some tumors are likely to involve intrapleural metastasis and some others not. However, there is a total lack of data on this field of pleural research.

Although there is strong evidence for the need to study the efficacy of antiangiogenic compounds, few studies report results from such medications in patients with metastatic pleural effusion from lung carcinoma; almost all studies are in animals. Several reasons may explain this fact. A major reason is that although antiangiogenic compounds showed activity in phase I and II studies, they failed to fulfill the high expectations of significant survival improvement in patients with advanced NSCLC. In large controlled trials, only a few patients responded to therapy, with little benefit in terms of disease-free survival. Also, clinical trials often do not include patients with metastatic pleural effusion, since they are difficult to assess, there is confusion regarding whether they are stage IIIb or IV as median survival in this patient population is poor, and metastatic pleural effusion is commonly refractory to chemotherapy. Another important reason may be the significantly increased levels of VEGF in the pleural fluid of such patients, necessitating probably higher doses of antiangiogenic compounds than those needed to treat other metastatic sites or primary tumors [59]. The lack of biological markers (either tissue or serum) to predict and monitor tumor response before and after induction of antiangiogenic therapy is another problem.

Indeed, VEGF monitoring in the blood has failed to predict the response of patients receiving angiogenesis antagonists in many controlled phase III trials, such as AVAIL and AVOREN [44]. The tissue assessment of microvascular density, reflecting the amount of vascular- ization in the tumor tissue, is believed to monitor the tumor response to angiogenic antagonists. In the case of metastatic pleural effusion, it is possible by direct vision with narrow band imaging to assess new vessel formation through a pleuroscope [60]. Although microvascular density has been confirmed by CD31 and CD34 staining on pleura tissue samples [60], it is questionable whether the degree of microvascular density is a determining factor of better response to antiangiogenic compounds or of survival $[36,37,61]$. A possible explanation of this lack of blood and tissue markers to predict treatment response might be tumor heterogeneity of patients included in clinical trials or research studies.

\section{Matrix Metalloproteinases}

In addition to VEGF, several molecules such as matrix metalloproteinases (MMPs), cyclooxygenase-2 (Cox-2) and angiopoietin-2 showed an inverse relationship with survival in lung cancer patients [47]. MMPs constitute a family of endopeptidases primarily responsible for the degradation and turnover of extracellular matrix. The proteolytic activity of MMPs targets components of the extracellular matrix, such as collagen, elastin, laminin and proteoglycans, and their action is restrained by specific tissue inhibitors of metalloproteinases (TIMPs) [62, 63]. MMPs are expressed by both normal stromal cells and cancer cells. An imbalance between the physiologic expression of MMPs and TIMPs has been reported in lung diseases, such as lung fibrosis, pleural effusions, acute respiratory distress syndrome and lung cancer $[64$, 65]. MMPs play an important role in tumor invasion and angiogenesis. Overexpression of various MMPs, such as MMP-2, MMP-9 and membrane type 1 stromelysin-3, is related to advanced-stage disease and poor survival in NSCLC patients [66, 67]. MMP-2, MMP-9 and TIMP have been tested in malignant and nonmalignant pleural effusions, since proteolytic activity may play an important role in the formation of pleural effusions by increasing vascular permeability. Controversy exists regarding whether both the level and expression of MMPs are significantly increased in tuberculous pleurisy and malignant pleural effusions compared to transudates $[65,68-$ 71]. Although pleural mesothelial cells have been suggested as the origin of MMPs, other cells also implicated in pleural pathology are able to produce MMPs, such as macrophages, monocytes, neutrophils, fibroblasts, tumor cells and even lymphocytes $[62,65,72,73]$. The relative responsibility of each cell for the production of MMPs in the pleural space varies according to the etiology of the pleural effusion [58], and this may be a possible explana- 
tion for the controversy. Therefore, to distinguish the different causes of pleural effusions by relying on the levels of metalloproteinases is not supported at this time.

Broad-activity inhibitors of MMPs, such as marimastat, batimastat and prinomastat, have been studied in clinical trials in different phases in patients with NSCLC. They globally showed poor activity, either as single agents or in combination with chemotherapy, in metastatic as in early-stage disease [74-76]. Few studies reported results from patients with malignant pleural effusion. In a phase I trial of intrapleural instillation of batimastat [77], toxicity was mild (fever and hepatitis) and not related to the dose or the blood levels of the compound. Sixteen out of the 18 patients showed improvement in the amount of pleural effusion, necessitating fewer pleural evacuation procedures [77]. However, it was unclear whether the local effect was due to a real local tumor response or simply to the action of batimastat as a sclerosing agent. The future of inhibitors of MMPs in the treatment of malignancies remains unclear and at least has to be redefined, since the current compounds tested gave poor results [75]. A possible explanation is that it is difficult to inhibit a complex system with multiple MMPs interacting using few compounds.

\section{Cyclooxygenase-2}

Cox is an important enzyme in the conversion of arachidonic acid to prostaglandins and is involved in maintenance and regulation of the immune response [78]. Two isoforms of Cox exist; Cox-1 is constitutionally expressed and Cox-2 is induced by growth factors, oncogenes, carcinogens and phorbol esters. Cox-2 is overexpressed early in various human malignancies including lung cancer, suggesting its possible role in carcinogenesis and that Cox-2 is linked to the development of cancer. In patients with NSCLC, overexpression of Cox-2 is associated with metastatic disease and worse prognosis [78]. Although several preclinical studies showed promising activity of Cox-2 inhibitors, both selective Cox-2 inhibitors (rofecoxib, celecoxib) failed to confirm significant benefit in terms of survival in patients with advanced NSCLC $[79,80]$. Moreover, rofecoxib was associated with significant cardiac toxicity [79]. Few studies exist reporting results of Cox-2 and the metabolites of its activation, such as prostaglandin $\mathrm{E}_{2}$, from lung cancer cells collected from pleural effusions [81]. In regard to the recent data from clinical trials of Cox-2 inhibitors, it is unlikely that those inhibitors, if tested, will provide any benefit in patients with NSCLC pleural effusion, at least in their current form.

\section{Conclusion}

Many molecular biomarkers have been studied recently in pleural effusion from lung carcinoma patients, yet few in relation to novel targeted compounds. Most of those studies concerned NSCLC, especially adenocarcinomas. As expected, the factor frequently studied in relation to the novel targeted compounds is EGFR, because of the recent development of TKIs. Although those studies reported interesting results, the relation between the EGFR mutational status on pleural fluid malignant cells and outcome of patients under TKIs is generally assessed retrospectively, in homogenous ethnic populations (Asiatic patients) with classically high rates of exon 19 and 21 mutations including relatively small numbers of patients and using different methodology. In fact, currently there is a lack of translation from basic research to immediate clinical routine practice, probably due to the different methodologies that have emerged in recent years. There is a lack of data on angiogenesis-related factors in relation to therapeutic applications of VEGF inhibitors. A major regret is the lack of studies on histological material, since we know the higher accuracy of large biopsies taken under direct vision by thoracoscopy. Overall, new molecular factors in pleural metastasis from lung carcinoma have a long path to follow from research studies to any therapeutic application. Clearly, there is a need for large studies correlating the molecular status of this patient population with novel molecular therapies. In particular, there is a need to study the molecular profile of tissue from pleural metastases compared to their primary tumor; this will lead to better understanding of the disease and possibly to more accurate therapeutic approaches. Currently, in patients with pleural effusion due to lung carcinoma, there are many more questions than answers.

\section{Financial Disclosure and Conflicts of Interest}

The author has no conflict of interest or funding source to declare in relation to this paper. 


\section{References}

1 Froudarakis ME: Diagnosis and management of pleural effusion in lung cancer; in Bouros D (ed): Pleural Diseases, ed 2. New York, Informa, 2009, pp 427-447.

$\checkmark 2$ Froudarakis ME, Briasoulis E: Advanced non-small cell lung cancer: on relapse rechallenge the tumor, not the patient. BMC Res Notes 2010;3:195.

-3 Johnston WW: The malignant pleural effusion. A review of cytopathologic diagnoses of 584 specimens from 472 consecutive patients. Cancer 1985;56:905-909.

4 Sahn SA: Malignancy metastatic to the pleura. Clin Chest Med 1998;19:351-361.

5 Froudarakis ME: Diagnostic work-up of pleural effusions. Respiration 2008;75:4-13.

6 Goldstraw P, Crowley J, Chansky K, Giroux DJ, Groome PA, Rami-Porta R, Postmus PE, Rusch V, Sobin L: The IASLC Lung Cancer Staging Project: proposals for the revision of the TNM stage groupings in the forthcoming (seventh) edition of the TNM Classification of malignant tumours. J Thorac Oncol 2007; 2:706-714.

7 Sugiura S, Ando Y, Minami H, Ando M, Sakai S, Shimokata K: Prognostic value of pleural effusion in patients with non-small cell lung cancer. Clin Cancer Res 1997;3:4750.

$>8$ Shepherd FA, Ginsberg RJ, Haddad R, Feld R, Sagman U, Evans WK, DeBoer G, Maki E: Importance of clinical staging in limited small-cell lung cancer: a valuable system to separate prognostic subgroups. The University of Toronto Lung Oncology Group. J Clin Oncol 1993;11:1592-1597.

$>9$ Livingston RB, McCracken JD, Trauth CJ, Chen T: Isolated pleural effusion in small cell lung carcinoma: favorable prognosis. A review of the Southwest Oncology Group experience. Chest 1982;81:208-211.

- 10 Perng RP, Chen CY, Chang GC, Hsia TC, Hsu NY, Tsai YH, Tsai CM, Yang CH, Chen YM, Yu CJ, Lee JJ, Hsu HS, Yu CT, Kao EL, Chiu CH: Revisit of 1997 TNM staging system - survival analysis of 1,112 lung cancer patients in Taiwan. Jpn J Clin Oncol 2007;37: 9-15.

$\checkmark 11$ Shepherd FA, Crowley J, Van Houtte P, Postmus PE, Carney D, Chansky K, Shaikh Z, Goldstraw P: The International Association for the Study of Lung Cancer lung cancer staging project: proposals regarding the clinical staging of small cell lung cancer in the forthcoming (seventh) edition of the tumor, node, metastasis classification for lung cancer. J Thorac Oncol 2007;2:10671077.

>12 Sriram KB, Relan V, Clarke BE, Duhig EE, Yang IA, Bowman RV, Lee YC, Fong KM: Diagnostic molecular biomarkers for malignant pleural effusions. Future Oncol 2011;7: 737-752.
13 Ishii S, Xu YH, Stratton RH, Roe BA, Merlino GT, Pastan I: Characterization and sequence of the promoter region of the human epidermal growth factor receptor gene. Proc Natl Acad Sci USA 1985;82:4920-4924.

14 Clark AJ, Ishii S, Richert N, Merlino GT, Pas$\tan$ I: Epidermal growth factor regulates the expression of its own receptor. Proc Natl Acad Sci USA 1985;82:8374-8378.

15 Froudarakis ME, Sourvinos G, Fournel P, Bouros D, Vergnon JM, Spandidos DA, Siafakas NM: Microsatellite instability and loss of heterozygosity at chromosomes 9 and 17 in non-small cell lung cancer. Chest 1998; 113:1091-1094.

16 Scagliotti GV, Selvaggi G, Novello S, Hirsch FR: The biology of epidermal growth factor receptor in lung cancer. Clin Cancer Res 2004; 10:4227s-4232s.

17 Giaccone G: The role of gefitinib in lung cancer treatment. Clin Cancer Res 2004;10: 4233s-4237s.

18 Shepherd FA, Rosell R: Weighing tumor biology in treatment decisions for patients with non-small cell lung cancer. J Thorac Oncol 2007;2(suppl 2):S68-S76.

19 Huang SF, Liu HP, Li LH, Ku YC, Fu YN, Tsai HY, Chen YT, Lin YF, Chang WC, Kuo HP, Wu YC, Chen YR, Tsai SF: High frequency of epidermal growth factor receptor mutations with complex patterns in non-small cell lung cancers related to gefitinib responsiveness in Taiwan. Clin Cancer Res 2004;10:8195-203.

20 Sonobe M, Manabe T, Wada H, Tanaka F: Mutations in the epidermal growth factor receptor gene are linked to smoking-independent, lung adenocarcinoma. Br J Cancer 2005;93:355-363.

21 Shih JY, Gow CH, Yu CJ, Yang CH, Chang YL, Tsai MF, Hsu YC, Chen KY, Su WP, Yang PC: Epidermal growth factor receptor mutations in needle biopsy/aspiration samples predict response to gefitinib therapy and survival of patients with advanced nonsmall cell lung cancer. Int J Cancer 2006;118:963969.

22 Zhang X, Chang A: Somatic mutations of the epidermal growth factor receptor and nonsmall-cell lung cancer. J Med Genet 2007;44: 166-172.

23 Han HS, Eom DW, Kim JH, Kim KH, Shin HM, An JY, Lee KM, Choe KH, Lee KH, Kim ST, Koo JH, Lee HC, Lee OJ: EGFR mutation status in primary lung adenocarcinomas and corresponding metastatic lesions: discordance in pleural metastases. Clin Lung Cancer 2011;12:380-386.

24 Kalikaki A, Koutsopoulos A, Trypaki M, Souglakos J, Stathopoulos E, Georgoulias V, Mavroudis D, Voutsina A: Comparison of EGFR and K-RAS gene status between primary tumours and corresponding metastases in NSCLC. Br J Cancer 2008;99:923-929.
25 Kimura H, Fujiwara Y, Sone T, Kunitoh H, Tamura T, Kasahara K, Nishio K: High sensitivity detection of epidermal growth factor receptor mutations in the pleural effusion of non-small cell lung cancer patients. Cancer Sci 2006;97:642-648.

26 Asano H, Toyooka S, Tokumo M, Ichimura K, Aoe K, Ito S, Tsukuda K, Ouchida M, Aoe M, Katayama H, Hiraki A, Sugi K, Kiura K, Date H, Shimizu N: Detection of EGFR gene mutation in lung cancer by mutant-enriched polymerase chain reaction assay. Clin Cancer Res 2006;12:43-48.

27 Zhang X, Zhao Y, Wang M, Yap WS, Chang AY: Detection and comparison of epidermal growth factor receptor mutations in cells and fluid of malignant pleural effusion in nonsmall cell lung cancer. Lung Cancer 2008;60: 175-182.

28 Tsai TH, Su KY, Wu SG, Chang YL, Luo SC, Jan IS, Yu CJ, Yu SL, Shih JY, Yang PC: RNA is favorable for analyzing EGFR mutations in malignant pleural effusion of lung cancer. Eur Respir J 2012;39:677-684.

29 Wu SG, Gow CH, Yu CJ, Chang YL, Yang $\mathrm{CH}$, Hsu YC, Shih JY, Lee YC, Yang PC: Frequent epidermal growth factor receptor gene mutations in malignant pleural effusion of lung adenocarcinoma. Eur Respir J 2008;32: 924-930.

30 Kimura H, Fujiwara Y, Sone T, Kunitoh H, Tamura T, Kasahara K, Nishio K: EGFR mutation status in tumour-derived DNA from pleural effusion fluid is a practical basis for predicting the response to gefitinib. $\mathrm{Br} \mathrm{J}$ Cancer 2006;95:1390-1395.

-31 Tanaka T, Nagai Y, Miyazawa H, Koyama N, Matsuoka S, Sutani A, Huqun, Udagawa K, Murayama Y, Nagata M, Shimizu Y, Ikebuchi K, Kanazawa M, Kobayashi K, Hagiwara $\mathrm{K}$ : Reliability of the peptide nucleic acidlocked nucleic acid polymerase chain reaction clamp-based test for epidermal growth factor receptor mutations integrated into the clinical practice for non-small cell lung cancers. Cancer Sci 2007;98:246-252.

32 Riely GJ, Pao W, Pham D, Li AR, Rizvi N, Venkatraman ES, Zakowski MF, Kris MG, Ladanyi M, Miller VA: Clinical course of patients with non-small cell lung cancer and epidermal growth factor receptor exon 19 and exon 21 mutations treated with gefitinib or erlotinib. Clin Cancer Res 2006;12:839-844.

-33 Jian G, Songwen Z, Ling Z, Qinfang D, Jie Z, Liang T, Caicun Z: Prediction of epidermal growth factor receptor mutations in the plas$\mathrm{ma} /$ pleural effusion to efficacy of gefitinib treatment in advanced non-small cell lung cancer. J Cancer Res Clin Oncol 2010;136: 1341-1347. 
-34 Swiderek J, Morcos S, Donthireddy V, Surapaneni R, Jackson-Thompson V, Schultz L, Kini S, Kvale P: Prospective study to determine the volume of pleural fluid required to diagnose malignancy. Chest 2010;137:68-73.

-35 Rodriguez-Panadero F: Medical thoracoscopy. Respiration 2008;76:363-372.

- 36 Froudarakis ME: New challenges in medical thoracoscopy. Respiration 2011;82:197-200.

37 Froudarakis ME, Noppen M: Medical thoracoscopy: new tricks for an old trade. Respiration 2009; 78:373-374.

- 38 Arcila ME, Oxnard GR, Nafa K, Riely GJ, Solomon SB, Zakowski MF, Kris MG, Pao W, Miller VA, Ladanyi M: Rebiopsy of lung cancer patients with acquired resistance to EGFR inhibitors and enhanced detection of the T790M mutation using a locked nucleic acid-based assay. Clin Cancer Res 2011;17: 1169-1180.

39 Hung MS, Lin CK, Leu SW, Wu MY, Tsai YH, Yang CT: Epidermal growth factor receptor mutations in cells from non-small cell lung cancer malignant pleural effusions. Chang Gung Med J 2006;29:373-379.

-40 Soh J, Toyooka S, Aoe K, Asano H, Ichihara S, Katayama H, Hiraki A, Kiura K, Aoe M, Sano Y, Sugi K, Shimizu N, Date H: Usefulness of EGFR mutation screening in pleural fluid to predict the clinical outcome of gefitinib treated patients with lung cancer. Int J Cancer 2006;119:2353-2358.

-41 Chen P, Wang L, Liu B, Zhang HZ, Liu HC, Zou Z: EGFR-targeted therapies combined with chemotherapy for treating advanced non-small-cell lung cancer: a meta-analysis. Eur J Clin Pharmacol 2011;67:235-243.

- 42 Joerger M, Matter-Walstra K, Fruh M, Kuhnel U, Szucs T, Pestalozzi B, Schwenkglenks M: Addition of cetuximab to first-line chemotherapy in patients with advanced nonsmall-cell lung cancer: a cost-utility analysis. Ann Oncol 2011;22:567-574.

-43 Shiao TH, Chang YL, Yu CJ, Chang YC, Hsu YC, Chang SH, Shih JY, Yang PC: Epidermal growth factor receptor mutations in small cell lung cancer: a brief report. J Thorac Oncol 2011;6:195-198.

-44 Pircher A, Hilbe W, Heidegger I, Drevs J, Tichelli A, Medinger M: Biomarkers in tumor angiogenesis and anti-angiogenic therapy. Int J Mol Sci 2011;12:7077-7099.

-45 Yano S, Matsumori Y, Ikuta K, Ogino H, Doljinsuren T, Sone S: Current status and perspective of angiogenesis and antivascular therapeutic strategy: non-small cell lung cancer. Int J Clin Oncol 2006;11:73-81.

46 Cabebe E, Wakelee H: Role of anti-angiogenesis agents in treating NSCLC: focus on bevacizumab and VEGFR tyrosine kinase inhibitors. Curr Treat Options Oncol 2007;8:15-27.
47 Yano S, Nishioka Y, Goto H, Sone S: Molecular mechanisms of angiogenesis in nonsmall cell lung cancer, and therapeutics targeting related molecules. Cancer Sci 2003;94: 479-485.

48 Horn L, Sandler AB: Angiogenesis in the treatment of non-small cell lung cancer. Proc Am Thorac Soc 2009;6:206-217.

49 Cheng D, Rodriguez RM, Perkett EA, Rogers J, Bienvenu G, Lappalainen U, Light RW: Vascular endothelial growth factor in pleural fluid. Chest 1999;116:760-765.

50 Matsuyama W, Hashiguchi T, Mizoguchi A, Iwami F, Kawabata M, Arimura K, Osame M: Serum levels of vascular endothelial growth factor dependent on the stage progression of lung cancer. Chest 2000;118:948-951.

51 Zhou WB, Bai M, Jin Y: Diagnostic value of vascular endothelial growth factor and endostatin in malignant pleural effusions. Int J Tuberc Lung Dis 2009;13:381-386.

52 Cheng M, Chen Y, Yu X, Tian Z, Wei H: Diagnostic utility of LunX mRNA in peripheral blood and pleural fluid in patients with primary non-small cell lung cancer. BMC Cancer 2008;8:156.

53 Hsu IL, Su WC, Yan JJ, Chang JM, Lai WW: Angiogenetic biomarkers in non-small cell lung cancer with malignant pleural effusion: correlations with patient survival and pleural effusion control. Lung Cancer 2009;65: 371-376.

54 Yano S, Shinohara H, Herbst RS, Kuniyasu H, Bucana CD, Ellis LM, Fidler IJ: Production of experimental malignant pleural effusions is dependent on invasion of the pleura and expression of vascular endothelial growth factor/vascular permeability factor by human lung cancer cells. Am J Pathol 2000;157:1893-1903.

55 Matsumori Y, Yano S, Goto H, Nakataki E, Wedge SR, Ryan AJ, Sone S: ZD6474, an inhibitor of vascular endothelial growth factor receptor tyrosine kinase, inhibits growth of experimental lung metastasis and production of malignant pleural effusions in a nonsmall cell lung cancer model. Oncol Res 2006;16:15-26.

56 Grove CS, Lee YC: Vascular endothelial growth factor: the key mediator in pleural effusion formation. Curr Opin Pulm Med 2002;8:294-301.

57 Miserocchi G: Physiology and pathophysiology of pleural fluid turnover. Eur Respir J 1997;10:219-225.

58 Jantz MA, Antony VB: Pathophysiology of the pleura. Respiration 2008;75:121-133.

59 Pichelmayer O, Gruenberger B, Zielinski C, Raderer M: Bevacizumab is active in malignant effusion. Ann Oncol 2006; 17:1853.

60 Ishida A, Ishikawa F, Nakamura M, Miyazu YM, Mineshita M, Kurimoto N, Koike J, Nishisaka T, Miyazawa T, Astoul P: Narrow band imaging applied to pleuroscopy for the assessment of vascular patterns of the pleura. Respiration 2009;78:432-439.
61 Sessa C, Guibal A, Del Conte G, Ruegg C: Biomarkers of angiogenesis for the development of antiangiogenic therapies in oncology: tools or decorations? Nat Clin Pract Oncol 2008;5:378-391.

62 Murphy G, Docherty AJ: The matrix metalloproteinases and their inhibitors. Am J Respir Cell Mol Biol 1992;7:120-125.

63 Ray JM, Stetler-Stevenson WG: The role of matrix metalloproteases and their inhibitors in tumour invasion, metastasis and angiogenesis. Eur Respir J 1994;7:2062-2072.

64 O'Connor CM, FitzGerald MX: Matrix metalloproteases and lung disease. Thorax 1994;49:602-609.

65 Eickelberg O, Sommerfeld CO, Wyser C, Tamm M, Reichenberger F, Bardin PG, Soler M, Roth M, Perruchoud AP: MMP and TIMP expression pattern in pleural effusions of different origins. Am J Respir Crit Care Med 1997;156:1987-1992.

66 Passlick B, Sienel W, Seen-Hibler R, Wockel W, Thetter O, Mutschler W, Pantel K: Overexpression of matrix metalloproteinase 2 predicts unfavorable outcome in early-stage non-small cell lung cancer. Clin Cancer Res 2000;6:3944-3948.

67 Brown PD, Bloxidge RE, Stuart NS, Gatter KC, Carmichael J: Association between expression of activated 72-kilodalton gelatinase and tumor spread in non-small-cell lung carcinoma. J Natl Cancer Inst 1993;85:574578.

68 Di Carlo A, Terracciano D, Mariano A, Macchia V: Matrix metalloproteinase-2 and matrix metalloproteinase- 9 type IV collagenases in serum of patients with pleural effusions. Int J Oncol 2005;26:1363-1368.

69 Hoheisel G, Sack U, Hui DS, Huse K, Chan KS, Chan KK, Hartwig K, Schuster E, Scholz $\mathrm{GH}$, Schauer J: Occurrence of matrix metalloproteinases and tissue inhibitors of metalloproteinases in tuberculous pleuritis. Tuberculosis (Edinb) 2001;81:203-209.

70 Di Carlo A, Mariano A, Terracciano D, Mazzarella C, Galzerano S, Cicalese M, Cecere C, Macchia V: Gelatinolytic activities (matrix metalloproteinase-2 and -9) and soluble extracellular domain of Her-2/neu in pleural effusions. Oncol Rep 2007; 18:425-431.

71 Park KJ, Hwang SC, Sheen SS, Oh YJ, Han $\mathrm{JH}$, Lee KB: Expression of matrix metalloproteinase-9 in pleural effusions of tuberculosis and lung cancer. Respiration 2005;72: 166-175.

72 Johnatty RN, Taub DD, Reeder SP, Turcovski-Corrales SM, Cottam DW, Stephenson TJ, Rees RC: Cytokine and chemokine regulation of proMMP-9 and TIMP-1 production by human peripheral blood lymphocytes. J Immunol 1997;158:2327-2333.

73 Goetzl EJ, Banda MJ, Leppert D: Matrix metalloproteinases in immunity. J Immunol 1996;156:1-4. 
74 Shepherd FA, Giaccone G, Seymour L, Debruyne C, Bezjak A, Hirsh V, Smylie M, Rubin S, Martins H, Lamont A, Krzakowski M, Sadura A, Zee B: Prospective, randomized, double-blind, placebo-controlled trial of marimastat after response to first-line chemotherapy in patients with small-cell lung cancer: a trial of the National Cancer Institute of Canada-Clinical Trials Group and the European Organization for Research and Treatment of Cancer. J Clin Oncol 2002;20: 4434-4439.

-75 Bissett D, O’Byrne KJ, von Pawel J, Gatzemeier U, Price A, Nicolson M, Mercier R, Mazabel E, Penning C, Zhang MH, Collier MA, Shepherd FA: Phase III study of matrix metalloproteinase inhibitor prinomastat in non-small-cell lung cancer. J Clin Oncol 2005;23:842-849.
76 Douillard JY, Peschel C, Shepherd F, PazAres L, Arnold A, Davis M, Tonato M, Smylie M, Tu D, Voi M, Humphrey J, Ottaway J, Young K, Vreckem AV, Seymour L: Randomized phase II feasibility study of combining the matrix metalloproteinase inhibitor BMS-275291 with paclitaxel plus carboplatin in advanced non-small cell lung cancer. Lung Cancer 2004;46:361-368.

77 Macaulay VM, O’Byrne KJ, Saunders MP, Braybrooke JP, Long L, Gleeson F, Mason CS, Harris AL, Brown P, Talbot DC: Phase I study of intrapleural batimastat (BB-94), a matrix metalloproteinase inhibitor, in the treatment of malignant pleural effusions. Clin Cancer Res 1999;5:513-520.

78 Brown JR, DuBois RN: Cyclooxygenase as a target in lung cancer. Clin Cancer Res 2004; 10:4266s-4269s.

-79 Gridelli C, Gallo C, Ceribelli A, Gebbia V, Gamucci T, Ciardiello F, Carozza F, Favaretto A, Daniele B, Galetta D, Barbera S, Rosetti F, Rossi A, Maione P, Cognetti F, Testa A, Di Maio M, Morabito A, Perrone F: Factorial phase III randomised trial of rofecoxib and prolonged constant infusion of gemcitabine in advanced non-small-cell lung cancer: the GEmcitabine-COxib in NSCLC (GECO) study. Lancet Oncol 2007;8:500-512.
80 Agarwala A, Fisher W, Bruetman D, McClean J, Taber D, Titzer M, Juliar B, Yu M, Breen T, Einhorn LH, Hanna N: Gefitinib plus celecoxib in chemotherapy-naive patients with stage IIIB/IV non-small cell lung cancer: a phase II study from the Hoosier Oncology Group. J Thorac Oncol 2008;3: 374-379.

81 Pace E, Siena L, Ferraro M, Profita M, Mondello P, Chiappara G, Montalbano AM, Giarratano A, Bonsignore G, Gjomarkaj M: Role of prostaglandin E2 in the invasiveness, growth and protection of cancer cells in malignant pleuritis. Eur J Cancer 2006;42: 2382-2389. 